\title{
Types of Explicitation within the Texts in Chinese-English Translation-A Case Study on the Translation of Chapter Titles of Hong Lou Meng ${ }^{*}$
}

\author{
Hong Guo \\ Foreign Languages College, Tianjin Normal University, Tianjin, China \\ Email: ghcncn2002@yahoo.com.cn
}

\begin{abstract}
Explicitation or explicitness means to make something implied explicit and clear. It is regarded as one of the translation universals and has been studied by many researchers all over the world. Because of the great difference between English and Chinese and their cultures, some different and special types of explicitation should be adopted in Chinese-English translation in order to meet the needs of the readers, the language and the function of the text. On the basis of detailed analysis of the translation of the chapter titles of Hong Lou Meng and the comparison of three translations, three types of explicitation commonly used within the text in Chinese-English translation come to the foreground. The three types of explicitation within the text are those of subjects, of cohesion and coherence and of grammatical meanings. This research may help translators in their Chinese-English translation practice.
\end{abstract}

Index Terms - explicitation, types, Chinese-English translation, chapter titles

\section{BACKGROUND AND PURPOSE}

Explicitation or explicitness means to make something implied explicit and clear, or to explain something. It "can be characterized in general terms as the phenomenon which frequently leads to TT stating ST information in a more explicit form than the original" (Shuttleworth \& Cowie, 1997, p.55). Since Baker (1993) pointed out that explicitation was one of the translation universals in 1993, much research has been done on it. For example, Cveras (1998), based on the analysis of English and Norwegian, found that, compared with the mother tongue, the translated language tended to be explicit" (Cited from Ke Fei, 2005, p.303, my translation). Chen Ruiqing (2004), after comparing the connectives used in the original Chinese texts and the translated texts in Taiwan Parallel Corpus, found that when paratactic Chinese was translated into hypotactic English, there was also a tendency of explicitation. Ke Fei (2005) studied both explicitness and implicitness in English-Chinese translation and pointed out that both are related to and caused by the translator, the language and the social and cultural differences. In 2006, Juiching Wallace Chen found in her PhD dissertation that explicitation was brought through the use of connectives in translated Chinese. Liu Yanshi in 2007 explained translation explicitation in its broad sense. He said that "explicitation, in its broad sense, does not only mean that of cohesive devices, but also includes that of meaning" (Liu, 2007, p.64, my translation). The explicitation of meaning should be usually brought by "adding the understandable (I've moved this word) overt expression and in various grammatical ways" (ibid, p.64, my translation), i.e. to make the implied information explicit by using language and grammatical forms. All of this research has set a solid foundation for the ongoing studies.

As is known, there are a lot of differences between English and Chinese and the two cultures. When the paratactic Chinese is translated into the hypotactic English, explicitation is "brought about by the translator filling out ST...motivated by the translator's conscious desire to explain the meaning to the TT reader..." (Shuttleworth \& Cowie, 1997, p.55). This has been testified as mentioned above. Is there anything special and in common in the explicitation in Chinese-English translation? Some Chinese researchers have found a few types, such as inserting notes, the use of scare quotes or an italic typeface...or an additional footnote... (Fan, 1996, p.139-143, cited from Chen, 2006), most of which are those outside the texts. "In her study of Dutch novels translated into English, Vanderauwera (1985) also identifies numerous types of explicitation..." (Chen, 2006, p.83), including both that within the texts (eg. addition of conjunctions) and outside (eg. insertion of explanatory items). This study will mainly focus on the explicitation within the texts in Chinese-English translation.

\section{MATERIALS USED}

\footnotetext{
* This study is part of the project of the Young and Middle Aged Key Faculty Research Abroad which was sponsored by Tianjin Municipal Education Commission and Tianjin Normal University.
} 
This study will be based on the comparison between the Chinese Chapter Titles of Hong Lou Meng and their three English versions ${ }^{1}$. The purpose of using these materials is twofold: to find the types of explicitation within the texts in Chinese-English translation and to find whether or not they are the same types.

Hong Lou Meng is one of the masterpieces of Chinese "Zhang Hui" novels, which is a special form in ancient Chinese literature. The novels are usually made up of many chapters each of which is a complete story and part of the whole one as well. Each chapter has its own title which shows the readers the outline or the theme of the whole chapter. Though it usually consists of one or two sentences, it is a text. For "TEXT is used in linguistics to refer to any passage, spoken or written, of whatever length, that does form a united whole" (Halliday \& Hasan, 1976, p.1). The one or two sentences of the title are a united whole with complete meaning. "The experience of meaningfulness correlated with successful integration during reading, which the reader projects back into the text as a quality of wholeness in its meaning" (Phelps, 1985, cited from Conner, 1990, p.1) can be brought by it. It can "build up a world picture around it" (Conner, 1990, p.13). So in this study we take them separately as examples (texts) to show the differences between English and Chinese and explicitation in translation.

The three English versions, which I use in this translation study are: the one translated by Bencraft Joly in 1892-1893 with the name of The Dream of the Red Chamber (henceforth, J's), the one by the couple Yang Xianyi and Gladys Yang in 1965-1974 with the name of The Dream of Red Mansions (Y's) and the one by David Hawkes and J. Minford in 1973-86 with the name of The Story of the Stone (H's). For Joly only translated the first 56 chapters, we only use the titles of the first 56 for the comparison, and among them chapter 18, 51,52,53 are missing, so there are altogether 52 chapter titles with 104 sentences used.

Chapter titles have vivid, colourful, rhythmic features and artistic and aesthetic value, so in titling, special attention is paid to the choice of words and sentence patterns. So many studies have been done especially on the patterns and features of Chinese chapter titles of Hong Lou Meng (Guo Jingwen 2007, Li Tao \& Xiao Weiqing 2006, Zhang Jie 2006,Wang Hongyin 2002, Liu Yongliang 1998, ect.). They found each title of the 120 chapters of Hong Lou Meng consists of two parallel eight-character sentences. And most of the sentences are made according to the pattern "323", named by Pro. Wang Hongyin (2002), which means a sentence made of three parts (phrases), the first with three characters, the second with two and the third with three. For example, 金陵城/起复/贾雨村. The first three-character part is the name of a city, the last is a person's name, and the two-character part in the middle is a phrase used as a predicate meaning "to recommend". In Chinese they are simply put together one after another, but they are "coherent with respect to context of situation...; and ...coherent with respect to itself, and therefore cohesive" (Halliday \& Hasan, 1976, p.23).

In order to help the western people understand the meaning of the title and the theme given, and still make it function as a title, the differences between the languages and cultures and the need of the readers must be considered. In this study we will compare not only the Chinese version with the English one, but also the three English versions with each other because as has been mentioned, the three were translated in different times and by translators from different social and cultural backgrounds. Though sometimes the three translators dealt with them a little bit differently, generally speaking, there are similarities in the ways of bringing explicitation into the texts, such as explicitation of subjects, of cohesion and coherence and of grammatical meanings.

\section{TyPES OF EXPLICITATION WITHIN THE TEXTS IN CHINESE-ENGLISH TRANSLATION}

In the following section, we will examine the three types of explicitation within the text in Chinese-English translation with the analysis of the titles of the Hong Lou Meng chapters in their Chinese version and their three English translations.

\section{A. Explicitation of Subjects}

Due to different aesthetic values existing in the eastern and western societies, English and Chinese, which belongs to two language systems, differ in many regards, first of all at the syntactical level.

In Chinese "there are many 'head and tail hidden' sentences because, according to the context and the logic, the subject, object or even predicate of a sentence is usually unnecessary and omitted..." While "in English, sentences are made basically on SVO structure, in which subject, object (if any) and predicate (apart from special patterns) are usually needed (主语、宾语甚至谓语在逻辑上往往承接前句而省略或干脆空缺, 造成许多“藏头匿尾”式的语 句...... 英语中每一单个的句子 (特殊句型除外)都严格遵循以 'SVO'为主体的句子结构原则, 句中的主语、谓语 和宾语(如果有宾语的话)基本上都是完备的)”(Liu, 2007, p.65, my translation).

Titles usually function as outlines of chapters, so most of the chapter titles in Hong Lou Meng are narratives. Though the subject is sometimes grammatically implied and sometimes not given, the sentence is still complete in meaning and meets the need of aesthetic value and rhythm. Considering the social and cultural differences, the readers' expectation and the communicative function, which are features peculiar to English, all the three translators make the most of subjects explicit. Here is an example: (pinyin is added above the Chinese words in order to show the rhythm of the titles. A slash "/" is used to separate the two sentences. $\mathrm{Ch}=\mathrm{Chinese,} \mathrm{EEq}=$ English words with equivalent meaning to the

\footnotetext{
1 The original and the three translations are taken from the corpus made by Yanshan University, China.
} 
Chinese characters. Some parts are highlighted with the bold or italic, as noted.)

Example 1: Ch: jīn 金 líng 陵 chéng 城 qǐ 起 fù 复 jiă 贾 yŭ 雨 cūn 村 / róng 荣 guó 国 fŭ 府 shōu 收 yăng 养 lín 林 dài 黛 yù 玉

EEq: Jinling City recommend Jia Yucun / Rong Mansion adopt Lin Daiyu

Y's: Lin Ruhai ${ }^{2}$ Recommends a Tutor to His Brother-in-Law The Lady Dowager ${ }^{3}$ Sends for Her Motherless Grand-Daughter

H's: Lin Ru-hai recommends a private tutor to his brother-in-law And old Lady Jia extends a compassionate welcome to the motherless child

J's: Lin Ru-hai appeals to his brother-in-law, Chia Cheng, recommending Yu-ts'un, his daughter's tutor, to his consideration-Dowager lady Chia sends to fetch her granddaughter, out of commiseration for her being a motherless child.

In Chinese title, both “金陵城”and“荣国府”are adverbs showing the places. “起复”and “收养” are predicates (the bold, henceforth the same) of the sentences. “贾雨村” and “林黛玉”are objects of the two verbs. These three show the readers the most important "wh"s_- what, where and who - of the story. Without the subjects, which in fact is implied in the adverbs, the meaning of the Chinese sentences is complete and clear. But if they are translated directly into English without the subjects, they are, first of all, grammatically incorrect. Besides, they may not be understood, so all three of the translators add subjects (the italic, henceforth the same) Lin Ruhai (林如海) and Old Lady Jia (贾母), which make the sentences readable and meaningful.

In the following translations, the same strategy is adopted.

Example 2: Ch: kāi 开 shēng 生 miàn面 mèng 梦 yăn 演 hóng 红 lóu楼 mèng 梦 / lì 立 xīn 新 chăng 场 qíng 情 chuán 传 huàn 幺𠃌 jìng 境 qíng 情

EEq: The first time in dream show Hong Lou Meng/ In new setting through love send fairy riddles

Y's: The Spiritual Stone 4 Is Too Bemused to Grasp the Fairy ' s Riddles The Goddess of Disenchantment in Her Kindness Secretly Expounds on Love

H's: Jia Bao - yu visits the Land of Illusion And the fairy Disenchantment performs the ' Dream of Golden Days.

J's: The spirit of Chia Pao-yu visits the confines of the Great Void - The Monitory Vision Fairy expounds, in ballads, the Dream of the Red Chamber.

This chapter is about how Jia Baoyu met the fairy in his dream, was led by her to know the story of "the dream of red mansions" and “the twelve beauties in Jinling", and to experience love for the first time. “开生面” means “the first time”, and “立新场” “the new place”; “梦”means “in the dream”, and “情” “through love experience”. All are adverbs in the sentences, but the verbs with their modifier imply the participants (doers). The participant of “梦演” and “开生 面” is Jia Baoyu, while that of “情传” and “立新场” is the fairy. So in the translation of the sentences, the subjects are made explicit in order to meet the needs of English sentence structure and to make the expression meaningful. The only difference is that the first sentence of Y's translation is in passive voice (the underlined) because of the different verb chosen.

Example 3: Ch: qíng 情 zhōng 中 qíng 情 yīn因 qíng 情 găn感 mèi 妹 mèi 妹 / cuò 错 lǐ 里 cuò 错 yǐ以 cuò 错 quàn 劝 $\mathrm{g} \overline{\mathrm{e}}$ 哥 $\mathrm{ge}$ 哥

EEq: In affection and because of it, move sister/ In wrong deed and by it, persuade brother

Y's: Moved by Affection, Baoyu Moves His Cousin A Wrong Report Makes Baochai Wrong Her Brother

H's: A wordless message meets with silent understanding And a groundless imputation leads to undeserved rebukes

J's: Tai-yu loves Pao-yu with extreme affection; but, on account of this affection, her female cousin gets indignant. Hsueh P'an commits a grave mistake; but Pao-ch'ai makes this mistake a pretext to tender advice to her brother.

In this translation, the three translators show the relationship among the heroes and the story clearly by making the subjects of “感” and “劝” explicit.

From the examples above, we can draw a conclusion: in Chinese-English translation, in order to meet the needs of readers and clear expression, considering the differences of the two languages and social cultures, the translators always make explicit some parts of a sentence, which is mostly the subject, usually by adding it. In the 104 sentences (altogether 312 translated sentences) we compared, 34 (with 102 translated ones) are without subjects. And among their 102 translated sentences, 92 were translated by adding subjects. For the others, the implicit subject is shown through the change of sentence structures or the way of expression. For example:

Example 4: Ch: lóng 栊 cuì 翠 ān 庵 chá茶 pǐn 品 méi 梅 huā 花 xuě 雪 / yí 怡 hóng 红 yuàn 院 jié 劫 yù 遇 mǔ 母 huáng 蝗 chóng 虫

EEq: Green Lattice Nunnery tea sip, plum flower and snow /Happy Red Court rob and meet Granny L

Y's: Ваоуи Sips Tea in Green Lattice Nunnery Granny Liu Succumbs to Wine in Happy Red Court

H's: Jia Baо-yu tastes some superior tea at Green Bower Hermitage And Grannie Liu samples the sleeping

\footnotetext{
2 Lin Ruhai is the name of Lin Daiyu's father.

Old Lady Dowager (or Old Lady Jia) is the grandma of Jia Baoyu and Lin Daiyu.

${ }^{4} \mathrm{Jia}$ Baoyu is regarded as the spirit of stone for he was bone with a stone in his hands.
} 
accommodation at Green Delights.

J's: Chia Pao-yu tastes tea in the Lung Ts'ui monastery - Old goody Liu gets drunk and falls asleep in the I Hung court.

In the three translations, the subject of the first half is made explicit by adding it (Jia Baoyu); while in the second half, the object Grannie Liu (Old goody Liu), the implied participant, is transferred into the subject, even though different verbs ("succumb, samples, gets and falls") are used. For another example:

Example 5: Ch: lú 芦 xuě 雪 ān 庵 zhēng 争 lián 联 jí 即 jǐng 景 shī 诗 / nuăn 暖 xiāng 香 wù 坞 yă 雅 zhì 制 chūn 春 dēng 灯 mí 谜

EEq: Reed Snow Cottage vie collective poem/ Warm Scented Arbour fine make Lantern Riddles

Y's: In Reed Snow Cottage Girls Vie in Composing a Collective Poem In Warm Scented Arbour Fine Lantern Riddles Are Made

H's: Linked verses in Snowy Rushes Retreat And lantern riddles in the Spring In Winter Room(短语)

J's: In the Lu Hsueh pavilion, they vie with each other in pairing verses on the scenery-In the Nuan Hsiang village, they compose, in beautiful style, riddles for the spring lanterns.

In Y's translation of the second sentence, the passive voice is used to emphasize the object "lantern riddles"; $\mathrm{H}$ put the whole into phrases; while J adds "they" to make the subject clear. Though they use different ways in dealing with the sentence, making the subjects implied out in the texts is the universal technique they adopted. And by doing this, the meaning and the logic of the titles are obvious.

\section{B. Explicitation of Cohesion and Coherence}

Like cohesion, coherence is a network of relations which organize and create a text: cohesion is the network of surface relations which link words and expressions to other words and expressions in a text, and coherence is the network of conceptual relations which underlie the surface text (Baker, 1992, p.218).

As Conner (1990) said, "Cohesion is the term for overt grammatically describable links on the textual surface... whereas coherence is the quality that makes a text conform to a consistent world picture and is therefore summarizable and interpretable... They (cohesion and coherence) (my note) may be found just as well within a sentence as between sentences" (Conner, 1990, p.7). "We could say that cohesion is the surface expression of coherence relations, that it is a device for making conceptual relations explicit" (Baker, 1992, p.218). But this does not mean cohesive relation is only structural. It is in fact also semantic. "What cohesion has to do with is the way in which the meaning of the elements is interpreted" (Halliday \& Hasan, 1976, p.11). So a well-formed coherent text is more than a series of grammatical sentences lined up one after another like so many blocks in a row. The sentences in well-formed writing are more like pieces in a jigsaw puzzle; the sentences interlock, each sentence building on the preceding ones while at the same time advancing discourse. Coherent writing, then is dependent on how sentences fit together to form a whole. The fit is achieved by the way the elements are arranged within the sentences and the choice among the sentence patterns themselves (Conner, 1990, p.45).

Compared with English texts, which “...must have semantic coherence as well as sufficient signals of surface cohesion to enable the reader to capture the coherence" (Enkvist, 1978, p.126, cited from Conner, 1990, p.1), Chinese ones are usually "non-cohesive in form but coherent in meaning/spirit... Sentences in a Chinese text are connected together by their implied logic. Connectives, pronouns and lexical cohesion are seldom used" (Liu, 2007, p.66). This means that sentences in Chinese texts fit together coherently with less or without cohesive devices. A text is usually organized and linked by meaning instead of by form.

All three of the translators noticed the difference between the two languages in this aspect and made the implied cohesive and coherent relation explicit in English, mainly by connection (including by using connectives, non-predicate forms, propositions and adverbial phrases), references and lexical cohesions (the italic in the following examples). For example, each title in Chinese consists of two sentences without any connectives in between narrating the series of things happening. In translating most of them, $\mathrm{H}$ put an "and" in each pair, and J used a dash to link them. But Y just kept them in parallel with an intention of introducing the Chinese way of chapter titling. The explicitation of cohesion and coherence can also be found in many other aspects.

Example 6: Ch: qíng 情 zhōng 中 qíng 情 yīn因 qíng 情 găn感 mèi 妹 mèi 妹 / cuò 错 lǐ 里 cuò 错 y̌̃ 以 cuò 错 quàn 劝 $g \overline{\mathrm{e}}$ 哥 $g \overline{\mathrm{e}}$ 哥

EEq: affection in affection and because of it, move sister / Wrong deed in wrong deed and by it, persuade brother

Y's: Moved by Affection, Baoyu Moves His Cousin A Wrong Report Makes Baochai Wrong Her Brother

H's: A wordless message meets with silent understanding And a groundless imputation leads to undeserved rebukes.

J's: Tai-yu loves Pao-yu with extreme affection; but, on account of this affection, her female cousin gets indignant.

Hsueh P'an commits a grave mistake; but Pao-ch'ai makes this mistake a pretext to tender advice to her brother.

In Y's translation, the relationship between the participants is realized by the references "his (sister)" and "her (brother)”. “情中情”, an adverb showing the reason is made explicit by the past participle phrase "moved by affection". In J's translation, more than one explicit device is used. First, the use of the references, "her" and "this", makes the relationship of the participants and the sentence meaning clear. "This affection" is for the previous "extreme affection" and "this mistake" for "a grave mistake"; "her" in the first sentence refers to "Tai-yu", while in the second to 
"Pao-ch'ai". Second, the connective "but" used in each sentence indicates clearly a turning of the statement. Third, the propositional phrase "on account of" shows clearly its function of reason. While in H's, lexical cohesion "wordless" and "groundless" is used to show the relationship of the two sentences.

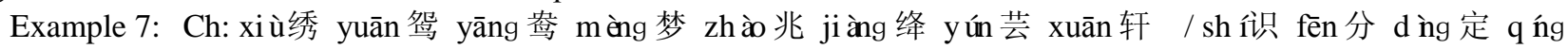
情 wù 悟 lí 梨 xiāng 香 yuàn 院

EEq: Embroider Mandarin Duck dream foretell Jiangyun Pavilion/ Know destiny, feeling arouse Pear Fragrance court

Y: A Dream During the Embroidering of Mandarin Ducks in Red Rue Studio Foretells the Future Baoyu Learns in Pear Fragrance Court That Each Has His Share of Love.

$\mathrm{H}$ : Bao-chai visits Green Delights and hears strange words from a sleeper Bao-yu visits Pear-tree Court and learns hard facts from a performer.

$\mathrm{J}$ : While Hsi Jen is busy embroidering mandarin ducks, Pao-yu receives, in the Chiang Yun Pavilion, an omen from a dream. Pao-yu apprehends that there is a destiny in affections, when his feelings are aroused to a sense of the situation in the Pear Fragrance court.

In this title, both “绛芸轩” and “梨香院” refer to the place. In both Y's and J's translations, the propositional phrases with “in” make the function clear. “绣然蓦” indicates the time when the thing happens. Y makes it explicit by using a propositional phrase with "during", while J does it by changing it into an adverbial clause directed by "while". H in his translation uses "and" to link the different things that happened.

Example 8: Ch: jīn 金 lán兰 qì 契 hù 互 pōu剖 jīn 金 lán兰 yǔ 语 / fēng 风 yǔ 雨 xī 夕 mèn 闷 zhì 制 fēng 风 yǔ 雨 cí 词

EEq: Girl friends talk each other heart-to-heart / Windy rainy evening, dully write verses

Y's: Two Girls Pledge Friendship After a Heart-to-Heart Talk A Plaintive Poem Is Written One Windy, Rainy Evening

H's: Sisterly understanding finds expression in words of sisterly frankness And autumnal pluviousness is celebrated in verses of autumnal melancholy.

J's: Friends interchange words of friendship - Tai-yu feels dull on a windy and rainy evening, and indices verses on wind and rain.

In the translation of this title, the explicitation of cohesion and coherence is mainly realized by lexical cohesion. Both $\mathrm{H}$ and $\mathrm{J}$ use repetition and synonyms to show the relationship of the two sentences. While in $\mathrm{Y}$ 's translation, the adverbial phrases directed by "after" and "one...evening" distinctively show clearly the logic of the two sentences.

All the examples above indicate that, in Chinese-English translation, in order to make the logic of the sentences clear enough, explicitation of cohesion and coherence is always necessary, and this kind of explicitation is usually realized by using connection, references and lexical cohesions. This kind of explicitation appeared in almost all the sentences we compared. But we should also notice that "when a SL is translated into a TL, there must be some tracks of the SL in the translated text (从一种语言翻译到另一种语言, 多少会存留一些源语的痕迹......)” (Wang \& Qin, 2009, p.102, my translation). Though "the cohesive and coherent models follow those of the target language in translation, they reflect a certain model used in the original in a certain degree as well (译文的衔接模式趋同于目的语, 同时译文一定程度上

（也会）反映原文衔接模式.......)”(Dong \& Zhang, 2006, p.59, my translation). Y's operations of the two sentences, H's translation in example 6, H and J's translations in example 8 are such examples. In doing so, the translators not only help the readers understand the text with ease, but also lead them to know the original language, thus experience the beauty conveyed by the language.

\section{Explicitation of Grammatical Meaning}

"By grammatical system, we refer to the devices we study in morphology and syntax: affixation, syntactic features, constructions such as clefting, topicalization, passive and middle, and other devices such as word order..." (Tara, 1999, p.8). "For every language it is necessary to consider grammatical form...and grammatical meaning...and the interrelationships of these..." (Platt, 1971, p. 63). In some languages, meaning (or events) is carried by a special form. English for instance, "...the distinction between past and present events is often signaled by verbal affixes..." (Tara, 1999, p.1). While other languages, "such as Chinese, Malay... have no formal category of tense or aspect. ...If necessary, time reference can be indicated by means of various particles and adverbials" (Baker, 1992, p.99). In Chinese, for example, different tenses are expressed by adverbials zhe(着), le( $)$ or $g u o($ 过). “...Because tense and aspect are not grammatical categories in Chinese..., tense and aspect distinctions may also take on additional, more subtle meanings in discourse" (Baker, 1992, p.99, 100).

Grammatical meaning here refers to the meaning given by grammatical inflections, such as plural of nouns, tense and voice of verbs. They indicate something more than the word itself. In English which is a synthetic language, these grammatical meanings are usually realized by the explicit change of word forms. While in Chinese, an analytic language, whose words lack grammatical inflection, the grammatical meaning or relation is usually realized through word order and function words or sometimes implied in the words used. In the analysis of the translations we found the grammatical meaning and relation of most chapter titles in Hong Lou Meng is realized this way. In order to meet the need of the readers and the language, most of them are made explicit by using grammatical inflections in the English 
translation. Look at the following examples (the word with implied grammatical meaning is bolded).

Example 9: Ch qín 秦 kě 可 qīng 卿 š̌ 死 fēng 封 lóng 龙 jìn 禁 wèi 尉 / wáng 王 xī 熙 fèng 凤 xié 协 lǐ 理 níng 宁 guó 国 fú 府

EEq: Keqing dies appoint the Imperial Guard / Wang Xifeng helps manage Ning Mansion

Y's: Keqing Dies and a Captain of the Imperial Guard Is Appointed Xifeng Helps to Manage Affairs in the Ning Mansion.

H's: Qin-shi posthumously acquires the status of a Noble Dame And Xi-feng takes on the management of a neighbouring establishment.

J's: Ch'in K'o-ch'ing dies, and Chia Jung is invested with the rank of military officer to the Imperial Body-guardWang Hsi-feng lends her help in the management of the Jung Kuo Mansion.

In Modern Chinese Dictionary, one of the explanation of the word “封” means that in ancient times, the king gave a peerage (sometimes including a piece of land) to his official. Even though the word is used without a subject, the meaning of the sentence is obvious. In this title, “龙禁尉” is the peerage. One of the themes shown in the title is the promotion of the family's status. So which king gave it or who was given is not as important as what was given. But in English the passive voice must be realized by grammatical inflection. So Y changes the order of the sentence and translates it into a passive voice, thus the relationship between “封” and “龙禁尉” is explicit, saving the effort to explain the complex relationship among people. $J$ also puts the sentence into passive voice with the recipient of the peerage “Chia Jung 贾敬” as the subject in order to show the theme. H's translation doesn't seem very exact. He may have partially misunderstood the meaning.

Example 10: Ch: jiă 贾 yuán 元 chūn 春 cái 才 xuăn 选 fèng 凤 zăo 藻 gōng 宫 / qín 秦 jīng 鲸 qīng 卿 yāo 天 shì 逝 huáng 黄 quán 泉 lù 路

EEq: Jia Yuanchun, Cairen, select Phoenix Palace / Qin Zhong die young, on the road to the heaven.

Y's: Yuanchun Is Selected as Imperial Consort in Phoenix Palace Qin Zhong Dying Before His Time Sets Off for the Nether Regions.

H's: Jia Yuan-chun is selected for glorious promotion to the Imperial Bedchamber And Qin Zhong is summoned for premature departure on the journey into Night.

J's: Chia Yuan-ch'un is , on account of her talents, selected to enter the Feng Ts'ao Palace-Ch'in Ching-ch'ing departs , in the prime of life, by the yellow spring road.

“才” for “才人” (Cairen), in ancient China, is a female officer and a princess as well. In chapter 4 of Hong Lou Meng, Cao Xueqin wrote:

Recently, to honour culture, encourage propriety and search out talent, in addition to selecting consorts and ladies-in-waiting the Emperor in his infinite goodness had made, the Board compile a list of the daughters of ministers and noted families from whom to choose virtuous and gifted companions for the princesses in their studies. (近因今上 崇诗尚礼, 征采才能, 降不世出之隆恩, 除聘选妃嫔外, 凡世宦名家之女, 皆亲名达部, 以备选为公主、郡主 入学陪侍, 充为才人、赞善之职。) (The bolded is my note.) (Y's translation)

Combined with the word “才” and “风藻宫” which is the royal palace, the word “选” implies a passive relationship with “贾元春”. So all the three translators put it into passive voice explicitly and the meaning and logic of the sentence is clear.

Example 11: Ch: xī 西 xiāng 厢 jì 记 miào 妙 cí 词 tōng 通 xì 戏 yǔ 语 / mǔ 牡 dān f tíng 亭 yàn 艳 qǔ 曲 jǐng 警 fāng 芳 xīn 心

EEq: The Western Chamber, lines, understand fun words / Peony Pavilion, songs, wake tender heart

Y"s: Lines from "The Western Chamber" Are Quoted in Fun A Song from "Peony Pavilion" Distresses a Tender Heart.

H"s: Words from the ' Western Chamber ' supply a joke that offends And songs from the ' Soul ' s Return ' move a tender heart to anguish.

J"s: Pao-yu and Tai-yu make use of some beautiful passages from the Record of the Western Side-building to bandy jokes - The excellent ballads sung in the Peony Pavilion touch the tender heart of Tai-yu.

Both The Western Chamber and Peony Pavilion are famous classical dramas in China. “妙词” and “艳曲” refer respectively to the dialogues and arias in the dramas. In Chinese both words “妙词” and “艳曲” can imply a single or plural meaning. But in the English translation they must be explicit to meet the needs of the sentence patterns. No matter how the translators understand them, everyone makes them explicit in his translations. “妙词” is regarded as a plural word and translated into "lines, words, passages" respectively; while “艳曲” is dealt with differently and translated into "a song" by Y, "songs" and "ballads" by H and J. The following examples belong to the same type.

Example 12: Ch: xiăng 享 fú 福 rén人 fú福 shēn深 huán还 dăo祷 fú福 / chīi疾 qíng 情 nü 女 qíng 情 zhòng 重 yù 愈 zhēn 勘 qíng 情

EEq: Happy man much happiness add happiness/ Infatuated girl much passion crave love.

Y's: Favourites of Fortune Pray for Better Fortune An Absurd, Loving Girl Falls Deeper in Love. 
H's: In which the greatly blessed pray for yet greater blessings And the highly strung rise to new heights of passion.

J's: A happy man enjoys a full measure of happiness, but still prays for happiness. A beloved girl is very much loved, but yet craves for more love.

“享福人” in Chinese refers to the kind of people who are lucky. In Y and H's translation, the plural meaning is made explicit, in Y with "favourites" and in $\mathrm{H}$ with "the + adj." structure. But J translates it in the single form to meet the needs of parallelism, “a happy man” with “a beloved girl”. “痴情女” in the second sentence refers to “林黛玉”. All the three translate it directly into the singular form which makes the meaning clear.

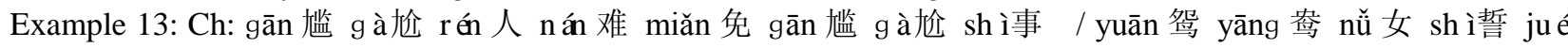
绝 yuān 鸳 yāng 尞 ǒu 偶

EEq: Embarrassed person can’t avoid awkward mission / Yuanyang vow never marry.

Y's: An Old Reprobate Makes an Unseemly Proposal Yuanyang Vows Never to Marry.

H's: An awkward person is given an awkward mission and a faithful maid vows faithfulness unto death.

J's: An improper man with difficulty keeps from improprieties - The maid, Yuan Yang, vows to break off the marriage match.

It is the same in this translation. Both “滥尤人” and “鹗莺女” refer to the exact persons in Chinese, so all the three deal with it in the same way.

\section{CONCLUSION}

Translation is a cross-cultural activity that has to meet the needs of the readers and communication. "In order to realize the expected function of translation, translator has to make choices (译者为实现译文的预期功能, 只能对信息 有所取舍)" (Yue, 2009, p.1, my translation). There is a great different between English and Chinese and their cultures. A great effort needs to be taken in Chinese-English translation, and explicitation within the text is the commonly used technique. Through the analysis of the titles in Hong Lou Meng chapters and their translations, we find that there are mainly three types of explicitation within a text in Chinese-English translation: explicitation of implied subjects, of cohesion and coherence and of grammatical meanings. They are made explicit in order to meet the need of the target readers, show the unity of form and meaning of the source texts and reach the goal of the translation. Besides, explicitation in translation always makes the complex stories and relationship among participants clear and meaningful in the target texts.

Explicitation is one of the universals in translation. In dealing with different kind of languages, there might be some features in common. Finding all these features may help the translators in their practice. We hope that the findings of our study will function similarly for the Chinese-English translation.

\section{REFERENCES}

[1] Baker, Mona. (1993). Corpus linguistics and translation studies: Implication and application. in M. Baker et al (ed.) Text and Technology: In Honour of John Sinclair. Amsterdam: John Benjamins.

[2] Baker, Mona. (1992). In Other Words - a coursebook on translation. Routledge: London \& Newyork.

[3] Blum-Kulka. (2000). Shifts in Cohesion and Coherence in Translation. In Lawrence Venuti (ed) Translation Studies Reader, Routledge: London \& Newyork.

[4] Chen Juiching Wallace. (2006). Explicitation Through the Use of Connectives in Translated Chinese: A Corpus-Based Study. A these submitted to the University of Manchester for the degree of Doctor of Philosophy in the Faculty of Humanities.

[5] Chen Ruiqing. (2004). The Tendency of Explicitation of Translated Chinese Text: A Corpus-based Study. A Symposium of the Ninth Translation and Interpreting Teaching Conference, Tainan: Translation Department of Changrong University.

[6] Conner Ulla \& Johns M. Ann. Ed. (1990). Cohesion in writing - research and Pedagogical perspectives. Teachers of English of Speakers of Other Languages, Inc. Alexandria, Virginia, Printed in the USA.

[7] Dong Guangcai \& Zhang Xiaofang. (2006). Translation Explicitation Under the Discourse Framework. The Journal of Xingtai Vocational Technology College, 8:58-60.

[8] Feng Dehe. (2009). Implication and Explication and their Losses in the Translation of Hong Lou Meng's Narrative Style. The Journal of Shandong Young Administrative Officials' College, 5:144-148.

[9] Guo Jingwen. (2007). Different Expressions and the Reasons in Chapter Titles in Hong Lou Meng. The Journal of Jiangxi Technology Normal College, 1:84-87, 90.

[10] Halliday, M.A.K. \& Ruqaiya Hasan. (1976). Cohesion in English. Longman.

[11] Ke Fei. (2005). Implication and Explication in Translation. Foreign Language Teaching and Research, 7:303-307.

[12] Li Tao \& Xiao Weiqing. (2006). The Complementation of "Knowing" and "Feeling"- the Analysis on the Aesthetic Features of Chapter Titles in Hawkes' Translation of Hong Lou Meng. Jiangxi Social Science 6:76-79.

[13] Liu Yanshi. (2007). Implication and Explication: A Study on Lin Yutang's English Translation of Six Chapters of a Floating Life in Aesthetic Perspective. The Journal of Sichuang Wenli College (Social Science), 5.

[14] Liu Yongliang. (1998). Language Aesthetics of Chapter Titles in Hong Lou Meng. Academic Periodical of Hong Lou Meng, 3:176-185.

[15] Liu Zequan \& Tian Lu. (2009). Narrative Marks in Hong Lou Meng and their Translation. Foreign Language Academic Periodical, 1:106-110.

[16] Mohanan Tara and Wee Lionel ed. (1999). Grammatical semantics-Evidence for structure in meaning. CSLI publication. 
[17] Nord, C. (2001). Translating as a Purposeful Activity. Shanghai Foreign Language Education Press.

[18] Nord, C. (2005). The Sense of Translation-Interpreting Skopostheory in Translation Study. Translated by Zhang Meifang \& Wang Kefei. Foreign Language Teaching and Research Press.

[19] Platt, T. John. (1971). Grammatical Form and Grammatical Meaning-A tagmemic view of Fillmore's deep structure case concepts. North-Holland Publishing Company: Amsterdam, London.

[20] Reiss, K. (2003). Translation Criticism: The Potentials and Limitations. Translated by Erroll F. R. United Kingdom: St. Jerome Publishing.

[21] Shuttleworth, Mark \& Cowie Moira. (1997). Dictionary of Translation Studies. Manchester: St. Jerome Publishing.

[22] Tang Xinliang. (2008). The Comparative study of the "Three Beauty" in the Two Translations of Hong Lou Meng. The Journal of Chongqing Science and Technology College (Social Science), 5:123-124.

[23] Wang Kefei \& Qin Hongwu. (2009). The Linguistic Features of English-Chinese Translation-A Macro Corpus-based Analysis. Foreign Language Academic Periodical, 1:102-105.

[24] Wang Hongyin. (2002). Comparative Study on the Rhetoric of Chapter Titles in the Two Translations of Hong Lou Meng. Foreign Language and Foreign Language Teaching, 1:54-57.

[25] Xiao, Z. \& T. McEnery. (2002). A corpus-based approach to tense and aspect in English-Chinese translation. Paper presented at International Symposium on Contrastive and Translation Studies between Chinese and English. Shanghai.

[26] Zhang Jie. (2006). Aesthetic Translation of Chapter Titles of Hong Lou Meng. The Journal of Huanan University (Social Science), 3

[27] Zhang Meifang. (2005). The Functional Approach in Translation Studies. Shanghai Foreign Language Education Press.

Hong Guo was born in Lanzhou, China in 1968. She received her M.A. degree in English Teaching from the Northwest Normal University, China in 1998.

She is currently an associate professor in the Foreign Languages College, Tianjin Normal University, Tianjin, China. Her research interests include translation theories and practice and translation teaching and training. 